\title{
Using GPS-IPW in a 4-D data assimilation system
}

\author{
Tracy L. Smith*, Stanley G. Benjamin, Barry E. Schwartz, and Seth I. Gutman \\ NOAA Forecast Systems Laboratory, Boulder, Colorado, U.S.A.
}

(Received December 31, 1999; Revised August 21, 2000; Accepted August 21, 2000)

\begin{abstract}
The NOAA Forecast Systems Laboratory (FSL) has been continuously calculating integrated atmospheric precipitable water (IPW) from GPS signal delays since 1994. Using rapid orbit information, these data have the accuracy required for use in a numerical weather prediction model through data assimilation. Parallel cycles with and without GPS-IPW data have been running at FSL since November 1997 using the 60-km Rapid Update Cycle (RUC). Verification of the analysis and the 3,6, and 12-h forecasts against rawinsondes has been ongoing throughout the experiment. Results from these statistics show a consistent improvement in short-range forecasts of relative humidity when the GPS data are included. Precipitation verification has also been calculated for this experiment, and results show that GPS data also improve these forecasts. Recently, the average number of available GPS observations jumped from 18 to 56, and results for November-December 1999 show that the previous slight positive signal is now amplified to a stronger positive impact on the short-range moisture forecasts.
\end{abstract}

\section{Introduction}

Due to insufficient observations, definition of atmospheric moisture fields (water vapor and cloud) remains a difficult problem whose solution is essential for improvement of weather forecasts. In the past few years, a largely unanticipated technique to estimate atmospheric integrated (total column) precipitable water (IPW) from Global Positioning System (GPS) signal delays has emerged (Duan et al., 1996). The magnitude of the signal delays caused by the neutral (i.e., nonpropagating) atmosphere depends on the refractive index associated with temperature, pressure, and water vapor. The "wet" component of the signal delay can be estimated using well-demonstrated techniques (Bevis et al., 1994) with an error of about $5 \%$ under all weather conditions (Wolfe and Gutman, 2000). FSL is now producing IPW estimates from a demonstration network of about 56 sites. This number is expected to grow to about 200 over the next $3-5$ years, mostly by incorporating GPS receivers deployed by other U.S. federal agencies for purposes unrelated to meteorology, such as improved positioning and navigation for enhanced land and marine transportation safety.

These GPS-IPW observations provide high-frequency, accurate observations unaffected by weather conditions, as tests by FSL and others have shown. Satellite-based water vapor estimates are also available, but have limitations. Those based on measurements of upwelling infrared radiation are reliable only in cloud-free areas. Those based on upwelling microwave radiation (available only over oceans) are valid in cloudy regions, but are less accurate than the IR-based estimates. The GPS-based IPW measurements are most valuable

*Affiliated with the Cooperative Institute for Research in the Atmosphere (CIRA).

Copy right(C) The Society of Geomagnetism and Earth, Planetary and Space Sciences (SGEPSS); The Seismological Society of Japan; The Volcanological Society of Japan; The Geodetic Society of Japan; The Japanese Society for Planetary Sciences. when satellites cannot obtain good measurements, mainly in cloudy regions where, from a forecasting perspective, the need for accurate measurements is high.

Using the original 60-km version of the Rapid Update Cycle (RUC, Benjamin et al., 1994), a data sensitivity study has been performed to examine the accuracy of IPW information and the impact of GPS-IPW observations on shortrange forecasts of moisture and precipitation. The RUC is an operational atmospheric prediction system, whose main components are a numerical forecast model and an analysis system to initialize that model. The RUC provides frequent short-range forecasts for forecast users in the United States. The version of the RUC used in this study produced new analyses and forecasts every $3 \mathrm{~h}$, always using the previous 3-h forecast as a background, and is described further in Sections 4 and 5. In order to gain a fair assessment of the impact of new observation systems, it is critical to determine the incremental value of the new system in the presence of other, already available observations. Since RUC already assimilated GOES (Geostationary Orbital Earth Satellite) precipitable water data, rawinsonde, and hourly surface moisture data, it is well-suited for such an investigation.

\section{Current and Future GPS-IPW Networks}

As of December 1999, data from 56 GPS-IPW systems are being acquired and processed by NOAA/FSL. These sites, located in the contiguous United States and Alaska (Fig. 1), consist of systems operated by NOAA and its affiliates, the U.S. Coast Guard (USCG), and the U.S. Department of Transportation (DOT) Highway and Railway Administrations. The use of GPS deployed by other U.S. federal agencies for atmospheric remote sensing results from a fortuitous overlap of requirements with the positioning and navigational applications of GPS by the USCG and U.S. DOT. Of special importance are the systems operated and maintained by the USCG along the U. S. coast of the Gulf of Mexico, since they 


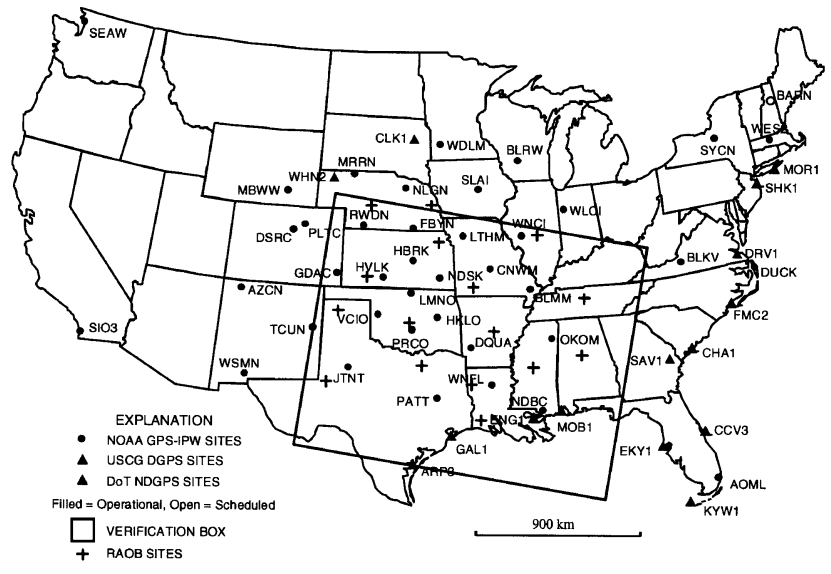

Fig. 1. The NOAA cooperative GPS network as of October 1999.

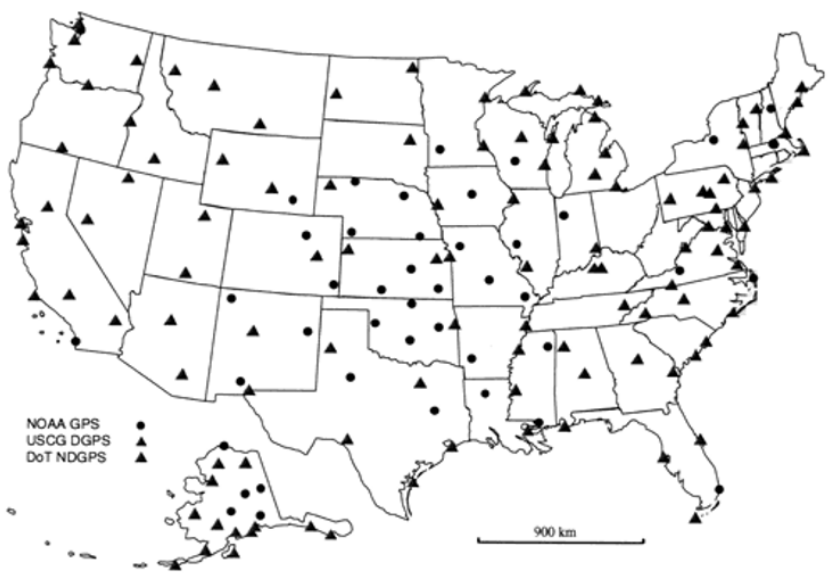

Fig. 2. The anticipated NOAA cooperative GPS network in 2003-2005.

provide additional water vapor observations near a relatively data-poor region.

The potential for expansion of the demonstration network in the next 3-5 years is illustrated in Fig. 2. Further expansion of the network from a demonstration system to an operational upper-air observing system is possible through the use of existing and planned installations belonging to NOAA and additional federal agencies, such as the National Weather Service and the Federal Aviation Administration.

\section{The Accuracy Requirement for GPS Precip- itable Water}

Despite there being no real-time moisture observations available in cloudy conditions other than 12-h rawinsondes (RAOBs) and surface observations, the skill of short-range precipitable water forecasts over the United States is reasonably good, especially away from coastal areas. A previous study (Benjamin et al., 1998b) using rapid orbit GPS IPW observations (Wolfe et al., 1998) and 3-h analyses from the 40-km RUC (Benjamin et al., 1998a) not assimilating those observations showed that the standard deviation difference was below $3 \mathrm{~mm}$ for all but coastal stations. Therefore, for GPS-IPW observations to enhance current information

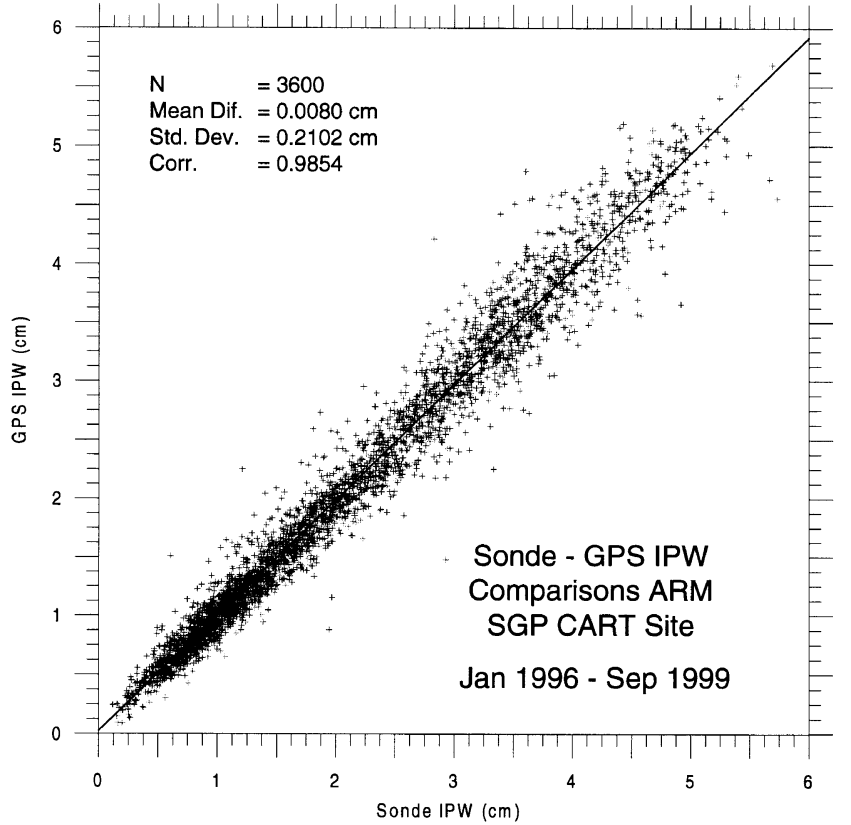

Fig. 3. Scatterplot of RAOB IPW vs. GPS IPW for 1996-1999.

away from U.S. coasts, GPS-IPW should have an accuracy of $<2 \mathrm{~mm}$ and closer to $1 \mathrm{~mm}$, if possible. A rapid orbit is defined as an improved GPS satellite orbit that is available 12-15 hours after the end of the day. Improved (with respect to the accuracy of "broadcast") orbits are required to reduce the errors in GPS-IPW measurements to acceptable limits.

Fortunately, such accuracy is possible by using 1) rapid orbits to calculate the GPS signal delay caused by the troposphere and 2) accurate surface pressure and temperature measurements to parse this delay into its dry and wet components. The dry delay is estimated using accurate collocated surface pressure measurements that are mapped into signal delay using the method described by Saastamoinen (1972). The wet delay is determined by subtracting the dry delay from the zenith-scaled tropospheric delay and mapping the resulting "zenith wet delay" into IPW using a mapping function that is nearly proportional to mean moisture-weighted temperature $\left(T_{m}\right)$ that is currently estimated using an empirical formula (Bevis, 1994). In the future, more accurate estimates of $\mathrm{T}_{\mathrm{m}}$ will come from the operational NCEP RUC model. Figure 3 shows a scatterplot of RAOB-IPW vs. GPSIPW for 1996-1999. The GPS-IPW observing system was located at the Lamont, OK NOAA Profiler site, $9 \mathrm{~km}$ north of the Atmospheric Radiation Measurement (ARM) Cloud and Radiation Testbed (CART) central facility where 3600 balloon launches took place over this period. The standard deviation between these two observation systems was about $2.1 \mathrm{~mm}$, with a mean difference of $0.08 \mathrm{~mm}$ and a correlation of 0.9854 , which includes measurement error for both systems as well as small-scale variability.

\section{Assimilation of Integrated Precipitable Water Data}

The RUC analysis method is multivariate optimal interpolation (OI), which accounts for the expected errors of both 
the observations and forecast background and weights the final result accordingly. The steps for including the GPS (and other) IPW data directly into the RUC OI scheme are shown below:

1) Calculate IPW horizontal field for the forecast background from water vapor mixing ratio at each level.

2) Calculate IPW residuals (difference between observations and background) at each IPW observation location. Only use GOES IPW where $\mathrm{p}_{\mathrm{sfc}}>950 \mathrm{hPa}$ to ensure that $\mathrm{p}_{\text {sfc }}$ from the observation retrieval is relatively close to that of the model.

3) Perform a two-pass univariate OI analysis of the IPW residuals of step 2 to produce an increment (correction to background) field, using a ratio of observational error standard deviation to the background error standard deviation of 0.1 for GPS-IPW (nonreal-time) and larger value for GOES IPW. The two passes use approximate e-folding correlation distances of $140 \mathrm{~km}$ and $67 \mathrm{~km}$, respectively, to allow both medium- and fine-scale structure.

4) At each horizontal grid point distribute the IPW increment calculated in step 3 vertically according to the background forecast profile of water vapor. Specifically, the absolute moisture at each level above a given horizontal grid location will be either increased or decreased by the same percentage, thus preserving the shape of the moisture profile.

5) If, after step 4, supersaturation occurs at any individual levels, adjust vertical distribution in the column so that a correct increase of PW is still achieved but without supersaturation.

6) Continue with the rest of the analysis, including that of single-level moisture observations. Thus, the nonintegrated moisture observations are given the "final say" in the moisture analysis.

This analysis procedure follows the general proposal of Gal-Chen et al. (1986), also used by Kuo et al. (1993), for assimilating vertically integrated quantities, that the background vertical structure be retained in that assimilation. In some studies concerning the assimilation of satellite-derived IPW data (Aune, 1994; Ledvina and Pfaendtner, 1995), the model background is adjusted to an analysis of the IPW observations. However, the adjustment proposed above is to an analysis of the IPW residuals to give a more accurate moisture analysis between IPW observations. Filiberti et al. (1994) showed successful experiments for assimilating SSM/I IPW values with an analysis technique equivalent to that proposed here using the French PERIDOT forecast model.

\section{Results from GPS-IPW Data Sensitivity Exper- iment}

To assess the impact of GPS-IPW observations, parallel cycles of the RUC assimilation system with and without GPS-IPW have been running at FSL since November 1997. The assimilation system is the original $60-\mathrm{km}$ RUC, with 25 vertical hybrid isentropic-sigma levels, and assimilation of observations every $3 \mathrm{~h}$ using the previous 3 -h forecast as background. The system ingests all available observations: RAOBs, wind profilers, ACARS (commercial aircraft) winds and temperatures, surface observations, and GOES precipitable water. Boundary conditions, from the Nested Grid

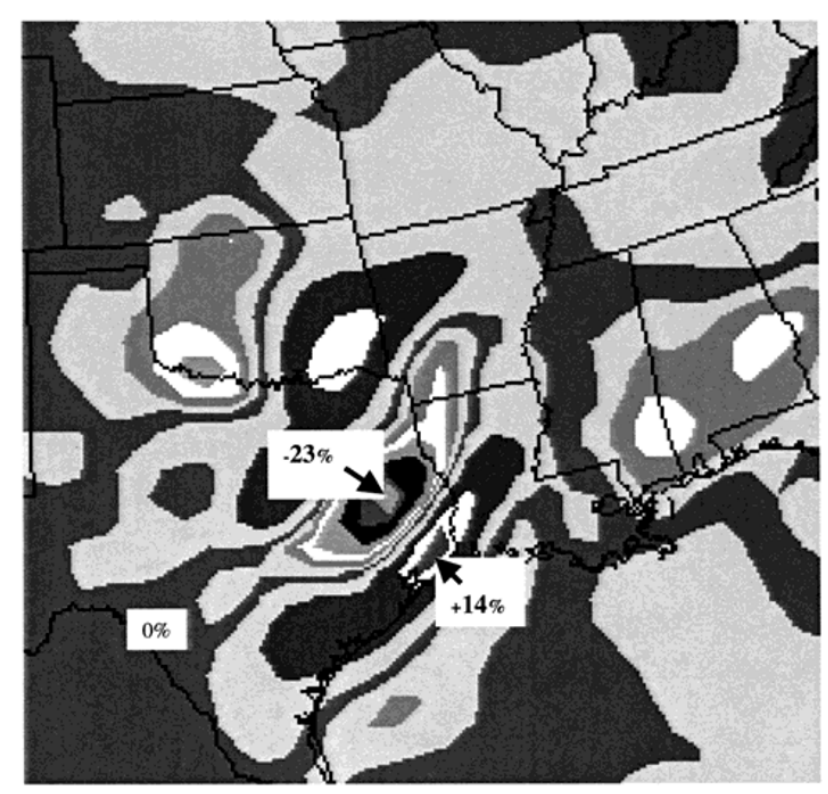

Fig. 4. RH difference field (\%), GPS-no GPS, for $850 \mathrm{hPa}$ at 0000 UTC 17 April 1998. The maximum increase in RH due to the inclusion of GPS data is marked by $+14 \%$ and the maximum decrease by $-23 \%$. Plot interval is $2 \%$.

\section{Relative Humidity 3-h Forecast Errors (Forecast- RAOB) 0000 UTC 17 April 1998}

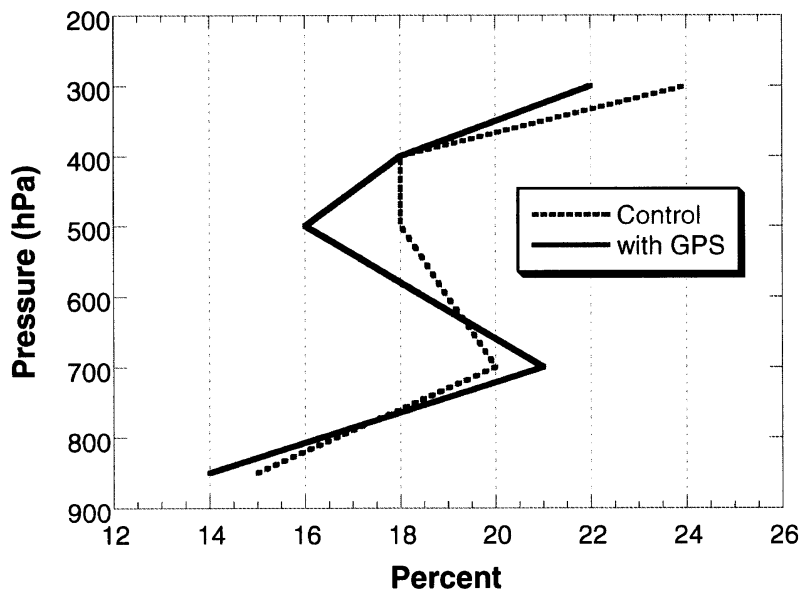

Fig. 5. RMS error verification statistics for RH over the verification area for 0000 UTC 17 April 1998. The solid line is the verification for the 3-h forecast from the GPS run compared to RAOBs. The dashed line is the verification for the control run 3 -h forecast.

Model, are also the same, except that the runs include or exclude GPS-IPW from the NOAA network. The cycles are run in a 24-h delay, so as to ingest the most accurate GPS-IPW calculated with rapid orbit information. Twice-daily verification of relative humidity $(\mathrm{RH})$ forecasts against RAOBs and daily verification of $24-\mathrm{h}$ precipitation amounts against a national precipitation gauge network have been ongoing for the duration of the experiment for a selected subdomain in the central and southern United States (Fig. 1, interior box). This area encompasses most of the initial and planned NOAA network at the start of the experiment. The chosen location 


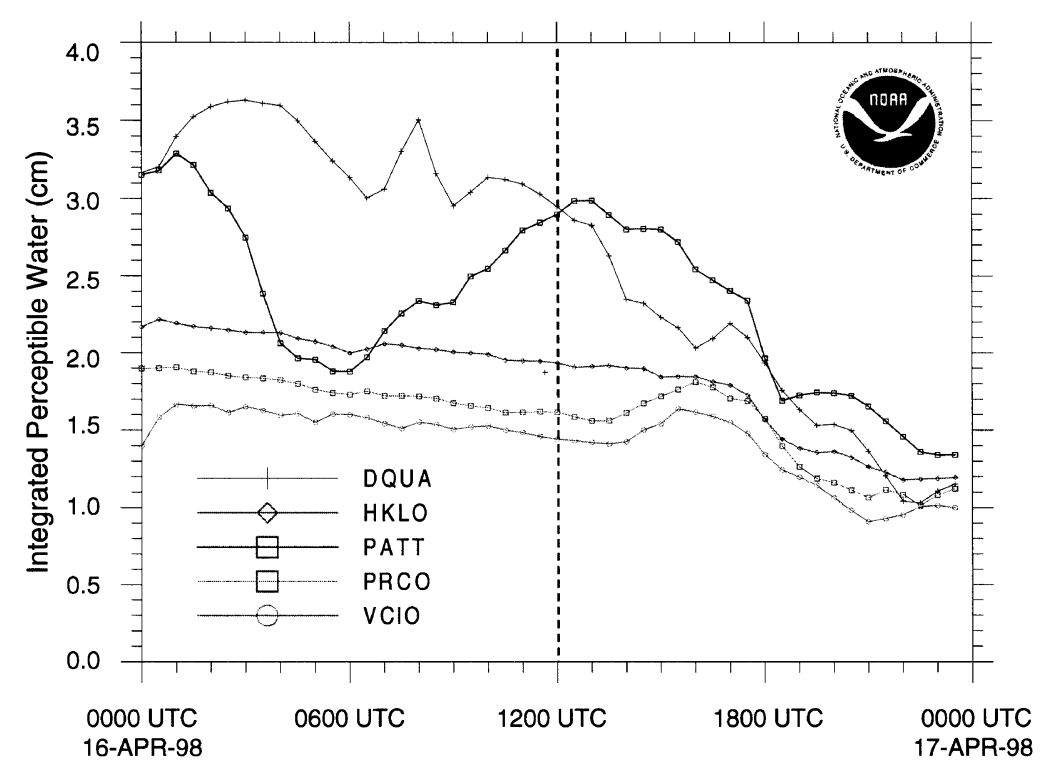

Fig. 6. Plot of GPS-IPW data (cm) at De Queen, AR (DQUA); Haskell, OK (HKLO); Palestine, TX (PATT); Purcell, OK (PRCO); and Vici, OK (VCIO) for 16 April 1998. The locations of these stations can be seen in Fig. 1.

and size of this verification box had to be large enough to obtain an adequate number of verifying observations, but not so large that the mesoscale signal of the GPS information was lost in the areal average. An example of the mesoscale changes in definition of the moisture field from assimilation of GPS-IPW is presented in Fig. 4, a difference field between the GPS and no GPS control runs in the verification area for a 3 -h forecast of $850 \mathrm{hPa}$ relative humidity $(\mathrm{RH})$ valid at 0000 UTC 17 April 1998. Most of the area has little change, but in eastern Texas the GPS data are moistening the RH ahead of a strong cold front by as much as $14 \% \mathrm{RH}$, and drying estimated RH behind the front by $23 \% \mathrm{RH}$. A plot of the $\mathrm{RH}$ verification numbers for this forecast averaged over the entire area (Fig. 5) shows that the overall impact of the GPS (solid line) was to improve the forecast by $1 \% \mathrm{RH}$ at $850 \mathrm{hPa}$ (the level in Fig. 4) and up to $2 \% \mathrm{RH}$ at $500 \mathrm{hPa}$, although the $700 \mathrm{hPa}$ forecast verified slightly worse with GPS. The mesoscale signal of the GPS, which was over $23 \% \mathrm{RH}$, has been dampened by the larger area of similar forecasts to the more modest numbers seen in the verification.

GPS data also have high temporal resolution, with observations available every half-hour. The data going into the $3 \mathrm{~h}$ assimilation cycle from 5 of the sites for this case study are shown in Fig. 6. The sharp decline in IPW at these sites between 1200 UTC 16 April 1998 (dashed line) and 0000 UTC 17 April due to the cold front (right of the dashed line) occurred between RAOB times.

The RH forecasts are verified on the mandatory pressure levels $(850,700,500,400,300 \mathrm{hPa})$; verification above 300 $\mathrm{hPa}$ is not performed due to known problems with the RAOB $\mathrm{RH}$ observations at upper levels. The number of GPS observations in the verification area averaged 15 , and the number of RAOB observations in the area averaged 18. The long-term average standard deviation difference between the RAOB and 3-h forecast RH for March 1998-September 1999 can be seen in Fig. 7. (Again, the solid line is the GPS run, and

\section{Relative Humidity 3-h Forecast Errors (Forecast- RAOB) March 1998-September 1999 (857 verification times)}

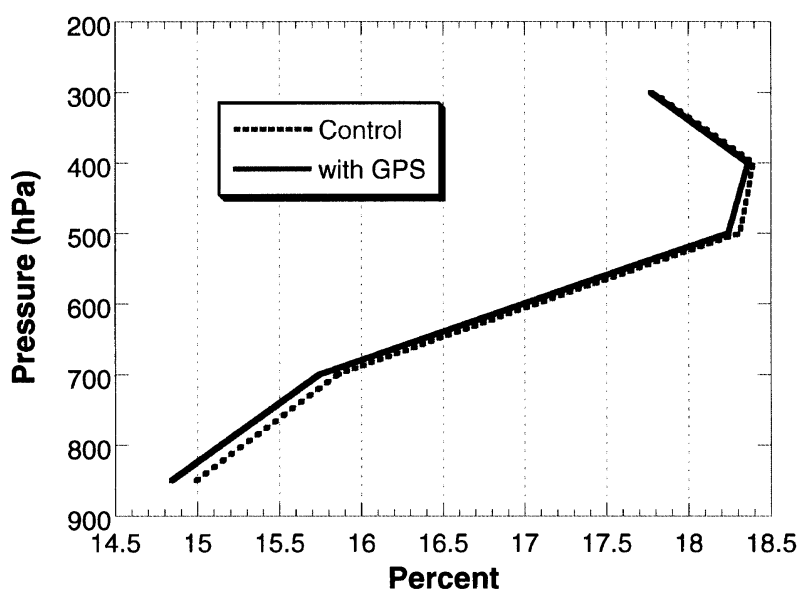

Fig. 7. Same as Fig. 5, but for March 1998-September 1999. These results are for an average of 15 RAOBs over 857 verification times, around 12,855 data points.

the dashed line is the control run.) This average contains 857 verification times, mostly from quiet weather regimes where the two runs verified similarly. Even so, the runs with GPS show a slight, but consistent improvement, despite the sparse observations over a large area.

The number of available GPS observations jumped in November 1999, with over 50 observations ingested regularly into the RUC system. Verification results from 15 November-15 December, 1999 indicate an amplification of the very slight positive signal that was evident from 18 GPS stations. The individual results of the available twice-daily verifications over this period (Fig. 8), show positive impact above the zero line, and negative impact below. The most frequent event in this twice-daily verification is when the two 
Table 1. Precipitation verification scores and biases for January-September 1999. (See text for explanation.)

\begin{tabular}{cccccc}
\hline $\begin{array}{c}\text { Number } \\
\text { of days }\end{array}$ & $\begin{array}{c}\text { Threshold } \\
\text { (in.) }\end{array}$ & ETS GPS & $\begin{array}{c}\text { ETS } \\
\text { Control }\end{array}$ & Bias GPS & $\begin{array}{c}\text { Bias } \\
\text { Control }\end{array}$ \\
\hline 93 & 0.10 & 0.154 & 0.157 & 1.06 & 1.01 \\
93 & 0.25 & 0.155 & 0.139 & 0.81 & 0.74 \\
85 & 0.50 & 0.095 & 0.089 & 0.47 & 0.45 \\
34 & 1.00 & 0.065 & 0.058 & 0.43 & 0.35 \\
16 & 1.50 & 0.048 & 0.045 & 0.94 & 0.87 \\
10 & 2.00 & 0.035 & 0.017 & 1.12 & 1.08 \\
\hline
\end{tabular}

$850 \mathrm{hPa}$ Relative Humidity 3-h forecast verification 15 Nov. - 15 Dec. 1999

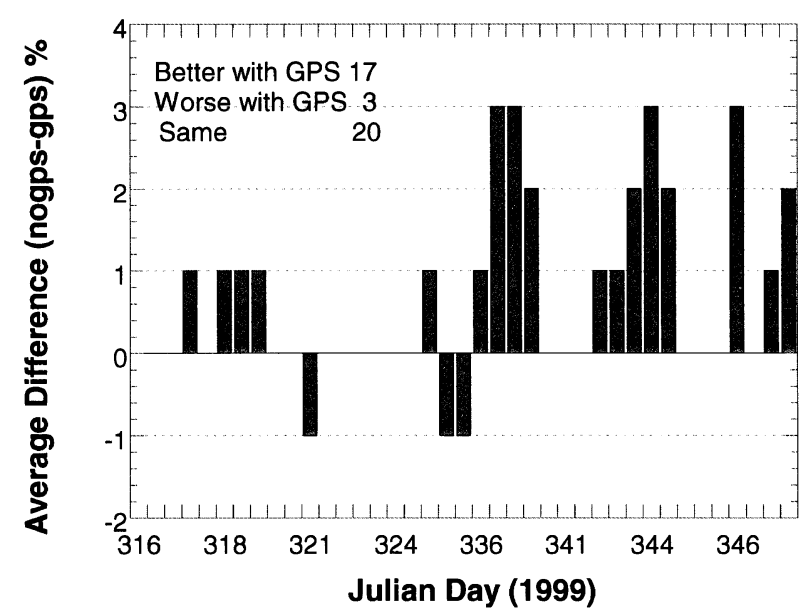

Fig. 8. Individual results for each verification time, 15 November-15 December 1999. Columns above the zero line denote positive impact from GPS data, and below show negative impact. The number of GPS sites for each time was around 50 .

cycles verified the same ( 20 out of 40 , or $50 \%$ ), but when the scores differ, the results are now almost always improved in the runs with GPS data, with 17 of 20 runs improved, in several cases by more than $1 \% \mathrm{RH}$, and just three negative cases, none worse than $1 \% \mathrm{RH}$.

Long-term precipitation verification has also been a part of the sensitivity study. Equitable threat score (ETS), bias, probability of detection (POD), and false alarm ratio (FAR) have all been calculated for 24-h precipitation for which RUC forecasts are produced by summing eight 3-h forecasts (accentuating possible effects on short-range forecasts). A detailed description of these parameters can be found in Doswell et al. (1990). The verifying observations were the 24-h totals from a national rain gauge network. Since the GPS data should have more impact during a weather event in the verification area, Table 1 shows verification for days with over 500 non-zero precipitation observations in the area from January-September 1999. Further, mean scores were calculated for each threshold only over the days there were at least some RUC 24-h forecasts exceeding those thresholds. The runs with GPS data have overall better ETS than the control runs, with comparable but slightly higher biases.
The RUC model used in these tests has some bias toward too little warm-season precipitation; GPS data often moistened the initial fields, increasing the precipitation coverage and amounts. In many instances this improved the forecasts, as can be seen by the improved bias scores. POD is also enhanced by the inclusion of GPS data, but does suffer from a higher FAR (not shown).

\section{Summary}

An observation sensitivity parallel-cycle test of the Rapid Update Cycle with and without GPS-IPW data is being run to examine impact of those data on short-range RUC forecasts. First discussed were several aspects of the use of GPS-IPW observations in operational numerical models. Since GPSIPW is available in cloudy conditions, its data are complementary to GOES precipitable water retrievals. From earlier studies, the required accuracy for IPW over a data-rich area such as the continental U.S. is estimated at about $1-1.5 \mathrm{~mm}$. A technique for incorporating GPS (and other) precipitable water observations into the RUC was described. Results from the long-term sensitivity study indicate that GPS data slightly improve forecasts of both relative humidity and precipitation. This impact was evident despite using only integrated moisture information, forcing a reliance on the model's estimate of relative vertical distribution of water vapor, and despite a minimal GPS network of 18 stations for most of the study. Recent results with a 56 station network showed a substantial increase in the positive impact. Because of the small network and transience of atmospheric moisture, the GPS-IPW observations have the most impact on short-range predictions, especially when there is active weather between 12-hourly RAOB observations. Initial considerations indicate that GPS-IPW may be an inexpensive but valuable addition to the composite atmospheric observing system. There is clearly a need to evaluate GPS in the current version of the RUC with a 1-h assimilation cycle with improved assimilation techniques, higher horizontal and vertical resolution, and improved moisture physics. This will allow better realization of potential for improved forecasts from the high timeresolution GPS observations. RUC assimilation improvements include a 3-d variational analysis that will assimilate IPW data simultaneously with other moisture observations rather than in the discrete steps now used and also assimilate satellite-derived cloud top information. Based on the results of this study, an even larger gain in impact from GPS IPW 
data will likely be evident in reconducting this experiment using further expansions in the network with more stations and greater horizontal coverage.

Acknowledgments. We thank John Brown and Nita Fullerton, as well as two anonymous reviewers, for their careful reviews of this paper.

\section{References}

Aune, R. A., Improved precipitation predictions using total precipitable water from VAS, 10th Conf. on Num. Wea. Pred., AMS, Portland, 192194, 1994.

Benjamin, S. G., K. J. Brundage, and L. L. Morone, The Rapid Update Cycle. Part I: Analysis/model description, Technical Procedures Bulletin No. 416, NOAA/NWS, 16 pp., 1994 [National Weather Service, Office of Meteorology, 1325 East-West Highway, Silver Spring, MD 20910].

Benjamin, S. G., J. M. Brown, K. J. Brundage, B. E. Schwartz, T. G. Smirnova, T. L. Smith, L. L. Morone, and G. J. DiMego, The operational RUC-2, 16th Conf. on Wea. Anal. and Forecasting, AMS, Phoenix, 249-252, 1998a.

Benjamin, S. G., T. L. Smith, B. E. Schwartz, S. I. Gutman, and D. Kim, Precipitation forecast sensitivity to GPS precipitable water observations combined with GOES using RUC-2, 12th Conf. on Num. Wea. Pred., AMS, Phoenix, 73-76, 1998b.

Bevis, M., S. Businger, S. Chiswell, T. A. Herring, R. A. Anthes, C. Rocken, and R. H. Ware, GPS meteorology: Mapping zenith wet delays onto precipitable water, J. Appl. Meteor., 33, 379-386, 1994.

Doswell, C. A., R. Davies-Jones, and D. L. Keller, On summary measures of skill in rare event forecasting based on contingency tables, Wea. Forecasting, 5, 576-585, 1990.
Duan, J., M. Bevis, P. Feng, Y. Bock, S. R. Chiswell, S. Businger, C. Rocken, F. Soldheim, R. H. Ware, T. A. Hering, and R. W. King, GPS meteorology: Direct estimation of the absolute value of precipitable water, J. Appl. Meteor, 35, 830-838, 1996.

Filiberti, M. A., L. Eymard, and B. Urban, Assimilation of satellite precipitable water in a meteorological forecast model, Mon. Wea. Rev., 122, 486-506, 1994.

Gal-Chen, T., B. D. Schmidt, and L. W. Uccellini, Simulation experiments for testing the assimilation of geostationary satellite temperature retrievals into a numerical prediction model, Mon. Wea. Rev., 114, 1213-1230, 1986.

Kuo, Y.-H., Y.-R. Guo, and E. R. Westwater, Assimilation of precipitable water measurements into a mesoscale numerical model, Mon. Wea. Rev., 121, 1215-1238, 1993.

Ledvina, D. V. and J. Pfaendtner, Inclusion of Special Sensor Microwave/ Imager (SSM/I) total precipitable water estimates into the GEOS-1 data assimilation system, Mon. Wea. Rev., 123, 3003-3015, 1995.

Saastamoinen, J., Introduction to practical computation of astronomical refraction, Bull. Geod., 106, 383-397, 1972.

Wolfe, D. E. and S. I. Gutman, Development of the NOAA/ERL GroundBased GPS Water Vapor Demonstration Network: Design and Initial Results, J. Atmos. Ocean. Technol., 2000 (in press).

Wolfe, D. E., S. I. Gutman, R. B. Chadwick, P. Fang, and Y. Bock, Development of an operational surface-based GPS water vapor observing system for NOAA: Network design and project status, 2nd Symp. on Int. Obs. Sys., AMS, Phoenix, J86-J91, 1998.

T. L. Smith (e-mail: traine@fsl.noaa.gov), S. G. Benjamin, B. E. Schwartz, and S. I. Gutman 